Proceedings

\title{
Influence of Temperature and Precipitation on the Climate Suitability of Severe Acute Respiratory Syndrome Coronavirus
}

\section{2}

\author{
Bi Wang ${ }^{1}$, Zheng Xin ${ }^{2,3, *}$ and Romaan Hayat Khattak ${ }^{4}$ \\ 1 College of Animal Science, Guizhou University, Guiyang 550000, China; wangbi19860520@163.com \\ 2 Tarim University, Alar 843300, P.R. China; zhengxin@nefu.edu.cn \\ ${ }^{3}$ Library of Northeast Forestry University, Harbin 150040, P.R. China; zhengxin@nefu.edu.cn \\ ${ }^{4}$ College of Wildlife and Protected Areas, Northeast Forestry University, Harbin 150040, P.R. China; \\ romaanktk@gmail.com \\ *Correspondence: zhengxin@nefu.edu.cn; Tel.: +86-136-1366-1018
}

Publisher's Note: MDPI stays neutral with regard to jurisdictional claims in published maps and institutional affiliations.

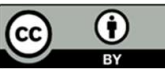

Copyright: $\odot 2020$ by the authors. Submitted for possible open access publication under the terms and conditions of the Creative Commons Attribution (CC BY) license (http://creativecommons.org/licenses/by/4.0/).

\begin{abstract}
The severe acute respiratory syndrome coronavirus 2 (SARS-CoV-2) pandemic has caused enormous losses worldwide since its emergence in 2019. We aimed to further understand how temperature and precipitation affect distribution of the virus, to facilitate taking preventive actions against the disease in a timely manner under varying climatic conditions. In this study, we used the MaxEnt model and R software to investigate temperature and precipitation factors that affect the fitness of SARS-CoV-2. Our results showed that low temperatures (approximately $0-17.5^{\circ} \mathrm{C}$ ) and low precipitation (approximately $30 \mathrm{~mm}$ ) greatly influence survival of the virus. However, the output value of the response curve was close to 1 with temperatures between $31^{\circ} \mathrm{C}$ and $37^{\circ} \mathrm{C}$ and monthly average precipitation $200 \mathrm{~mm}$, which indicates that a high risk of SARS-CoV-2 transmission may also exist under these environmental conditions. SARS-CoV-2 can easily survive under conditions of low temperature and low precipitation; however, the virus also presents a high risk at $31-37^{\circ} \mathrm{C}$ and monthly precipitation of $200 \mathrm{~mm}$. The results of this study provide a theoretical basis for predicting the spread of SARS-CoV-2.
\end{abstract}

Keywords: Severe acute respiratory syndrome coronavirus 2; Temperature; Precipitation; MaxEnt model; Akaike information criterion; True skill statistic.

\section{Introduction}

Health and surveillance systems worldwide have faced unprecedented challenges since the emergence of the coronavirus disease 2019 (COVID-19) pandemic at the end of 2019 [1] which continues to cause tremendous damage and loss to the international community [2]. At present, the source of the causative agent, severe acute respiratory syndrome coronavirus 2 (SARS-CoV-2), is not completely clear. It is generally believed that the virus spread from bats [3], pangolins [4] or other wild animals to humans and has subsequently spread among humans. According to recent clinical case reports, pet cats [5], tigers [6] and African lions [7] have been diagnosed with SARS-CoV-2 infection, making this pandemic is a huge challenge for the survival of humans and other animals.

SARS-CoV-2 can be spread through droplets when an infected patient coughs or sneezes, among other possible routes [8]. Common clinical manifestations of SARS-CoV2 infection include fever, dry cough, breathing difficulties (dyspnea), headache, severe respiratory illness, and pneumonia [3]. Serious illness can lead to progressive respiratory failure and death owing to alveolar damage [9](Hui et al., 2020). Transmission electron cryomicroscopy has revealed that the SARS-CoV-2 S protein binds angiotensin-converting enzyme 2 (ACE2) with higher affinity than does its predecessor, SARS-CoV [10]. 
Therefore, SARS-CoV-2 is more harmful to humans than SARS-CoV. Changes in global climate may have an important role in outbreaks of infectious diseases [11,12,13]. Previous research of malaria, dengue, chikungunya, Murray Valley encephalitis, Ross River, Rift Valley fever viruses, influenza, Varicella, hantavirus, and hand, foot and mouth disease (HFMD) have shown that extreme climate conditions are likely to affect the occurrence and spread of these diseases [12,14-23]. Research shows that temperature and precipitation climate variables have a significant influence on the occurrence of infectious disease epidemics [24]. Therefore, in the study of SARS-CoV-2, some researchers have analyzed the relationship of temperature and precipitation with the virus by calculating the $R$ value of Effective Reproductive Numbers [25] and Pearson's correlation analysis [26] .

The MaxEnt model adopts ecological niche modeling based on the maximum entropy theory first proposed by Phillips in 2004 [27]. This model can be used to analyze the niche needs of species and predict their potential geographic distribution using present or absent information of the target species and environmental data. In recent years, this model has been widely applied in the prediction of both human and animal infectious diseases and analysis of environmental factors in infectious diseases [28-32].

SARS-CoV-2 research is mainly focused on etiology and virus infectivity, clinical drug screening, and detection and traceability, among other aspects [9, 33-36]. Research is relatively lacking regarding important environmental variables and fitness analysis related to SARS-CoV-2. The arrival of the summer and autumn seasons may lead to resurgence in COVID-19 outbreaks. In this article, we aimed to analyze and discuss extreme values of temperature and precipitation that could affect SARS-CoV-2 transmission, using the MaxEnt model and R software package, based on the niche theory of pathogens. Our findings can provide a theoretical basis for future measures to prevent the spread of SARS$\mathrm{CoV}-2$ in regions around the world.

\section{Materials and Methods}

\subsection{Data sources and processing}

The geographic location of our study area was the site of the original outbreak of SARS-CoV-2 in Wuhan, China $\left(113^{\circ} 41^{\prime}-115^{\circ} 05^{\prime} \mathrm{E}, 2^{\circ} 58^{\prime}-31^{\circ} 22^{\prime} \mathrm{N}\right)$. We minimized the spatial auto-correlation between geographic locations [28], then extracted geographic locations within a 10-km range. At last, we got 289 geographic sites. We selected 19 biometeorological factors (bio-1 to bio-19) representing extreme values of temperature and precipitation, as environmental variables $[32,37]$, to further analyze the relationship of climate factors and risk of virus survival.

\subsection{Model construction and evaluation}

The model with the smallest corrected Akaike information criterion (AICc) value was calculated using the R package "ENMeval" (Cobos et al., 2019a, Muscarella et al., 2014). The AIC value (or $\triangle \mathrm{AIC}$ ) was calculated using the "lambdas" file in the MaxEnt model. Finally, the AIC value (or $\triangle \mathrm{AICC}$ ) was used to measure the complexity of the model with different combinations of MaxEnt (Cobos et al., 2019b). The MaxEnt model specifies the feature classes allowed $(\mathrm{L}=$ linear, $\mathrm{Q}=$ quadratic, $\mathrm{H}=$ hinge, $\mathrm{P}=$ product and $\mathrm{T}=$ threshold). The feature combinations (FCs) were set as L, H, LQ, LQH, LQPH, and LQPHT; the regularization multiplier (RM) was set at $0.5-4$ with an interval of 0.5 . The test and training sets were categorized as $25 \%$ and $75 \%$ of all data. We performed logistic regression with 10 replicates.

In this study, we used the area under the receiver operating characteristic (ROC) curve (AUC) value and average standard deviation to measure the accuracy of the model; we also used the R package "PresenceAbsence" to calculate the sensitivity and specificity of the model. PresenceAbsence was used to calculate the true skill statistic (TSS) of the predicted values of sample points and background points, to measure the sensitivity and specificity of the model. 


\section{Results}

\subsection{Model selection results}

The best model was selected, based on the AIC using ENMeval (Figure. 1 and Table S2). The FC was LQ and RM was 0.5.

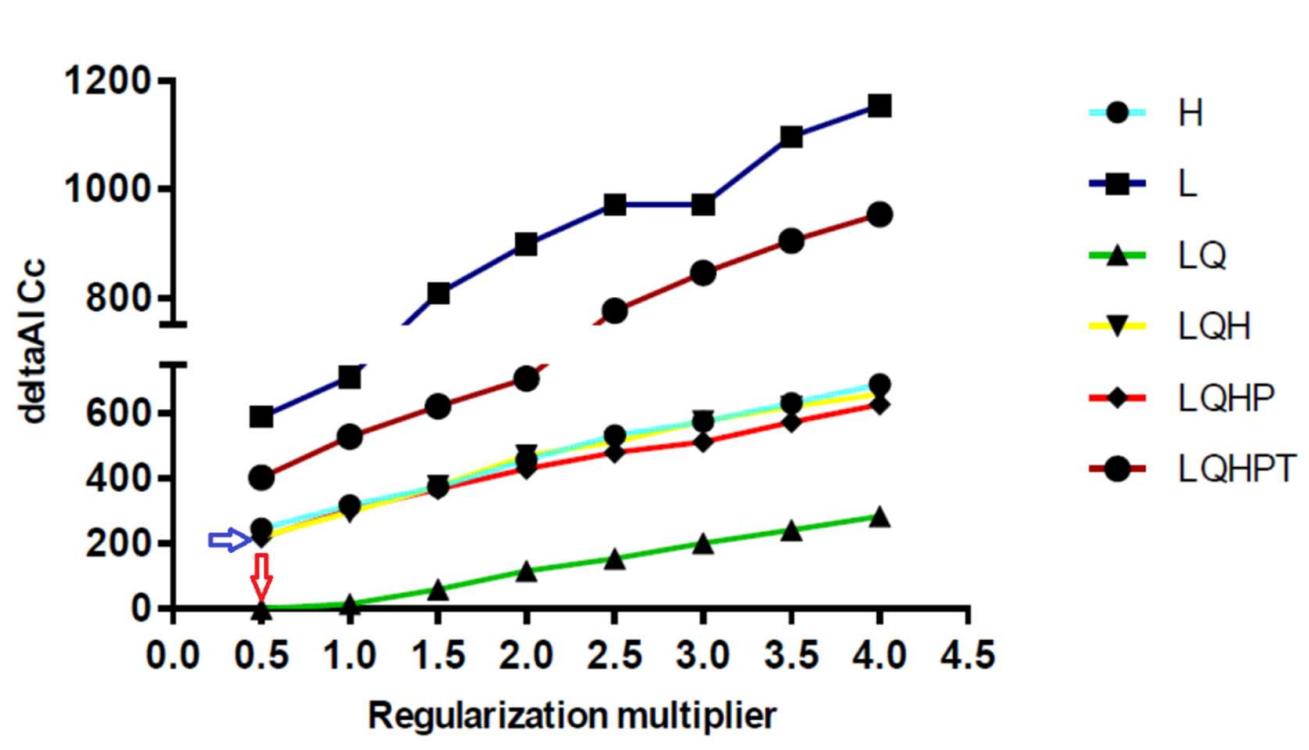

Figure 1. Default settings (LQHP) and settings (LQ) that yielded the minimum corrected Aikake information criterion (AICc) are indicated with arrows. Legends denote feature classes allowed ( $\mathrm{L}=$ linear, $\mathrm{Q}=$ quadratic, $\mathrm{H}=$ hinge, $\mathrm{P}=$ product and $\mathrm{T}=$ threshold). Note that for severe acute respiratory syndrome coronavirus 2 (SARS-CoV-2), AICc-selected settings (based on all localities) resulted in substantially lower omission rates than were achieved using the default settings.

\subsection{Response curve}

3.2.1. Temperature variable 
(a)
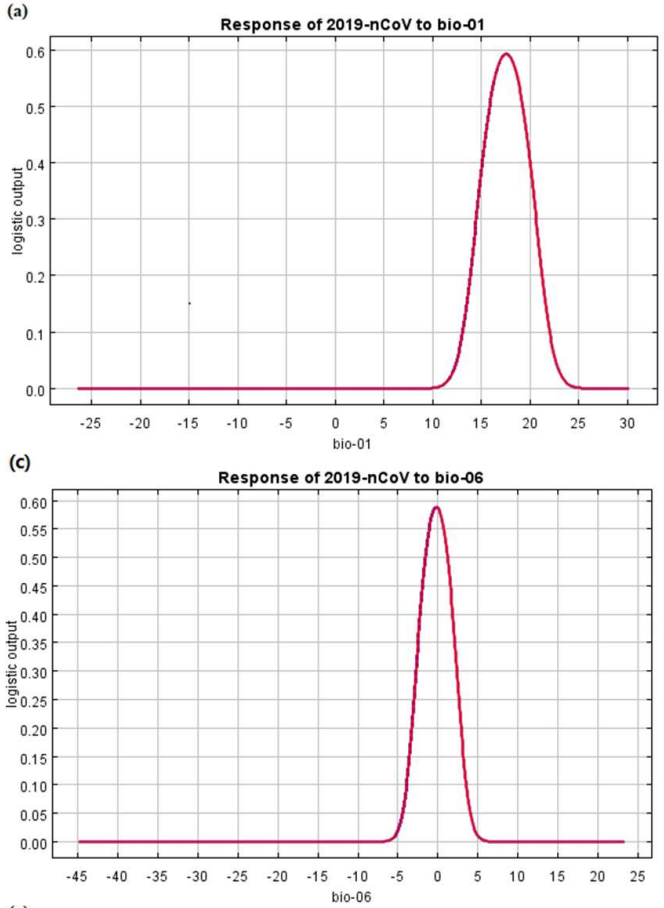

(e)
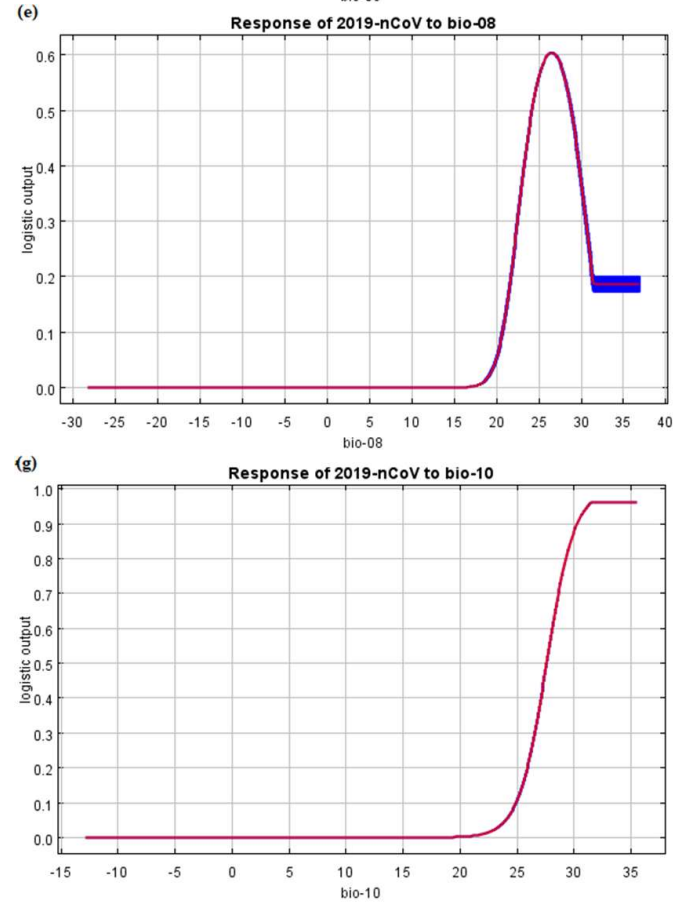

(b)

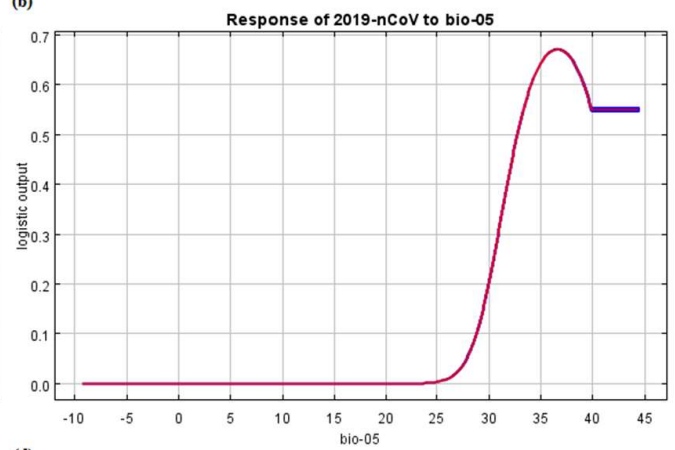

(d)

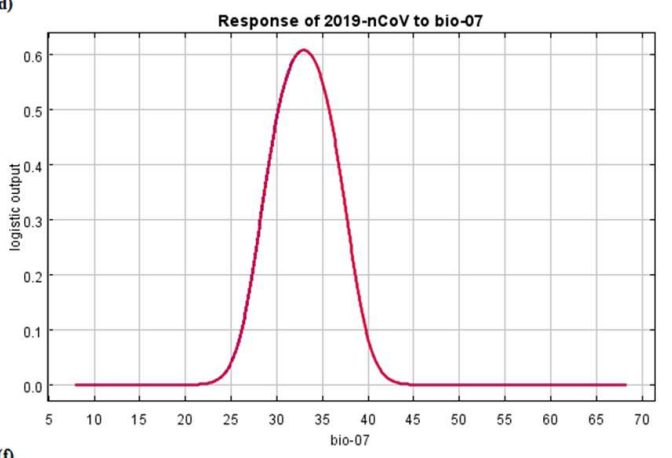

(f)

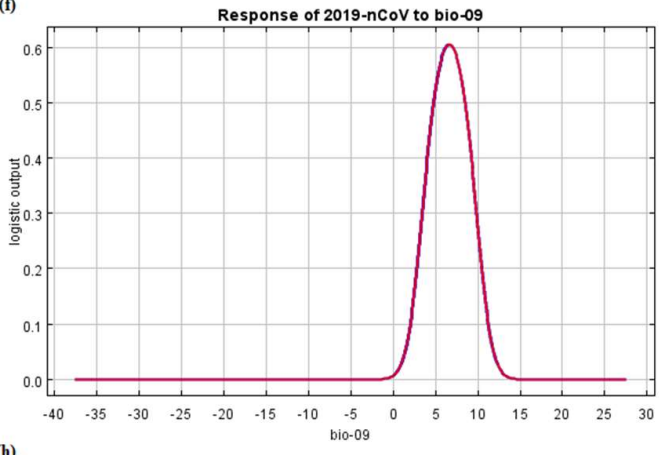

(h)

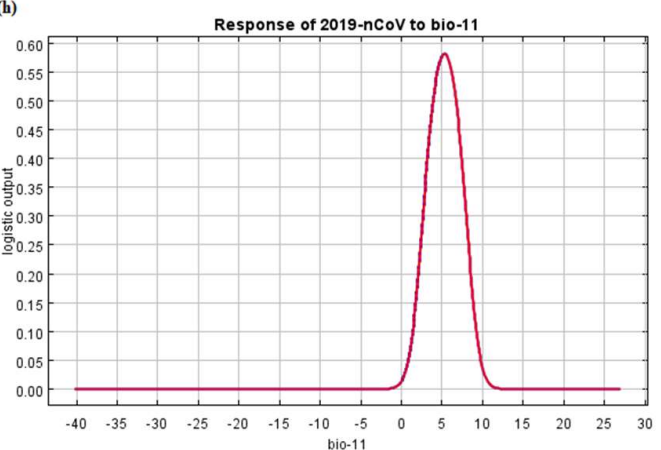

Figure 2. Response curves of biometeorological factors representing temperature.

In Figure. 2, peak response curves appear under the following conditions: when the annual mean temperature (bio-01) is approximately $17.5^{\circ} \mathrm{C}$, when the maximum temperature of the warmest month (bio-05) is approximately $37^{\circ} \mathrm{C}$, when the minimum temperature of the coldest month (bio-06) is approximately $0^{\circ} \mathrm{C}$, when the annual temperature range (bio-07) is approximately $32.5^{\circ} \mathrm{C}$, when the mean temperature of the wettest quarter (bio-08) is approximately $30^{\circ} \mathrm{C}$, when the mean temperature of the driest quarter (bio-09) is approximately $7^{\circ} \mathrm{C}$, when the mean temperature of the warmest quarter (bio-10) is ap- 
proximately $31.5^{\circ} \mathrm{C}$, or when the mean temperature of the coldest quarter (bio-11) is approximately $5^{\circ} \mathrm{C}$. In other words, the risk of a SARS-CoV-2 outbreak is highest under these temperature conditions. In addition, the peak logistic output values of bio- 05 and bio- 10 were higher than those of the other temperature variables (approximately equal to 0.6 ).

\subsubsection{Precipitation variable}

(a)

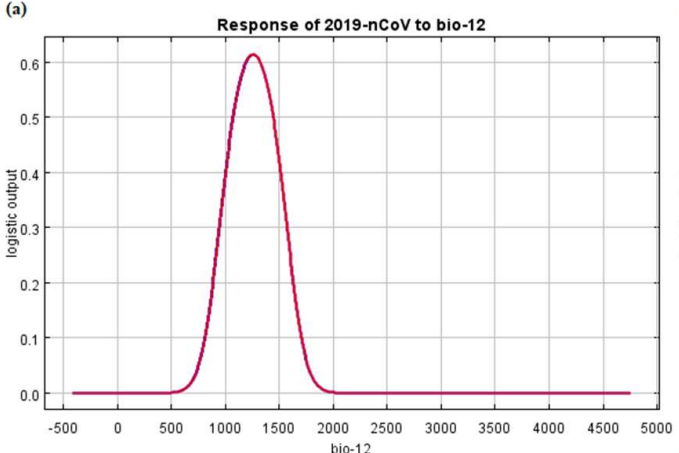

(c)

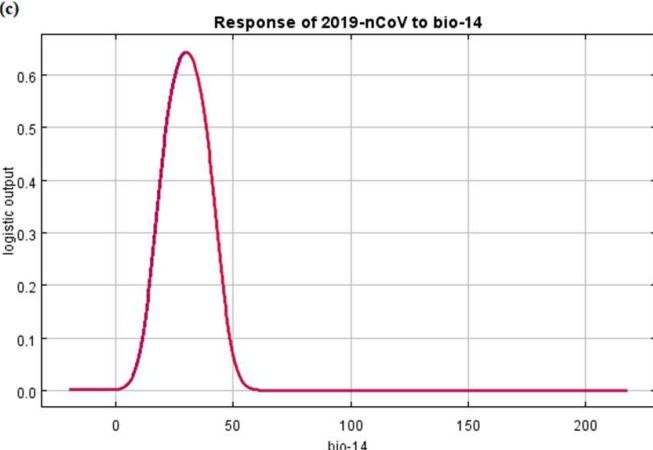

(e)
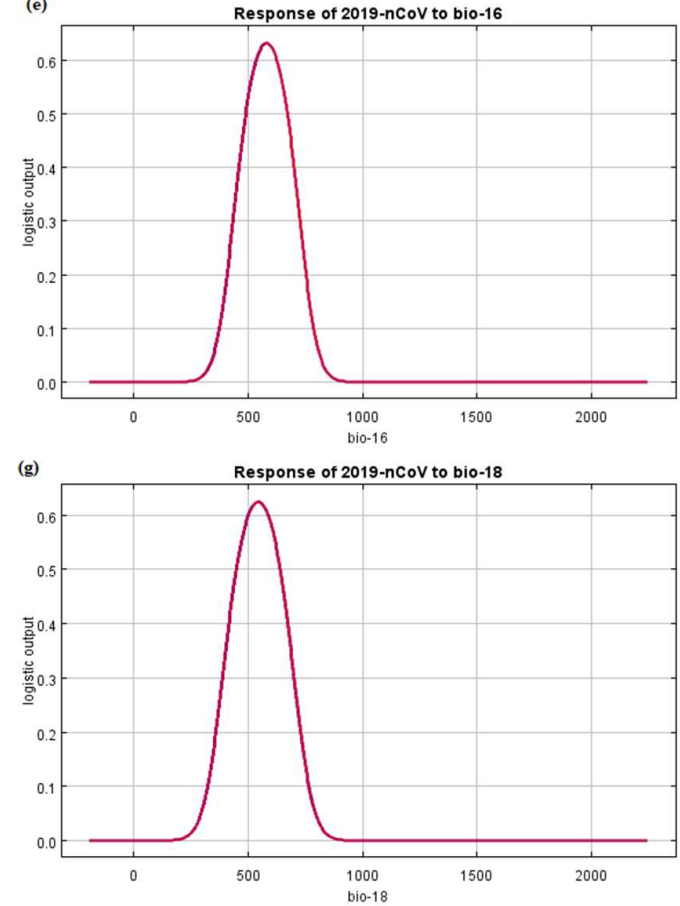

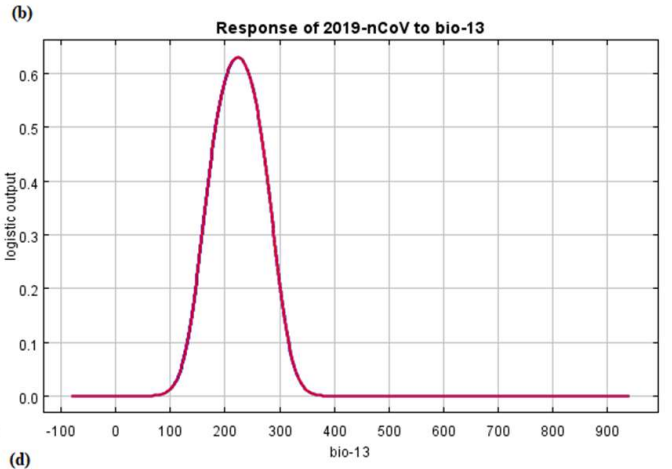

(d)
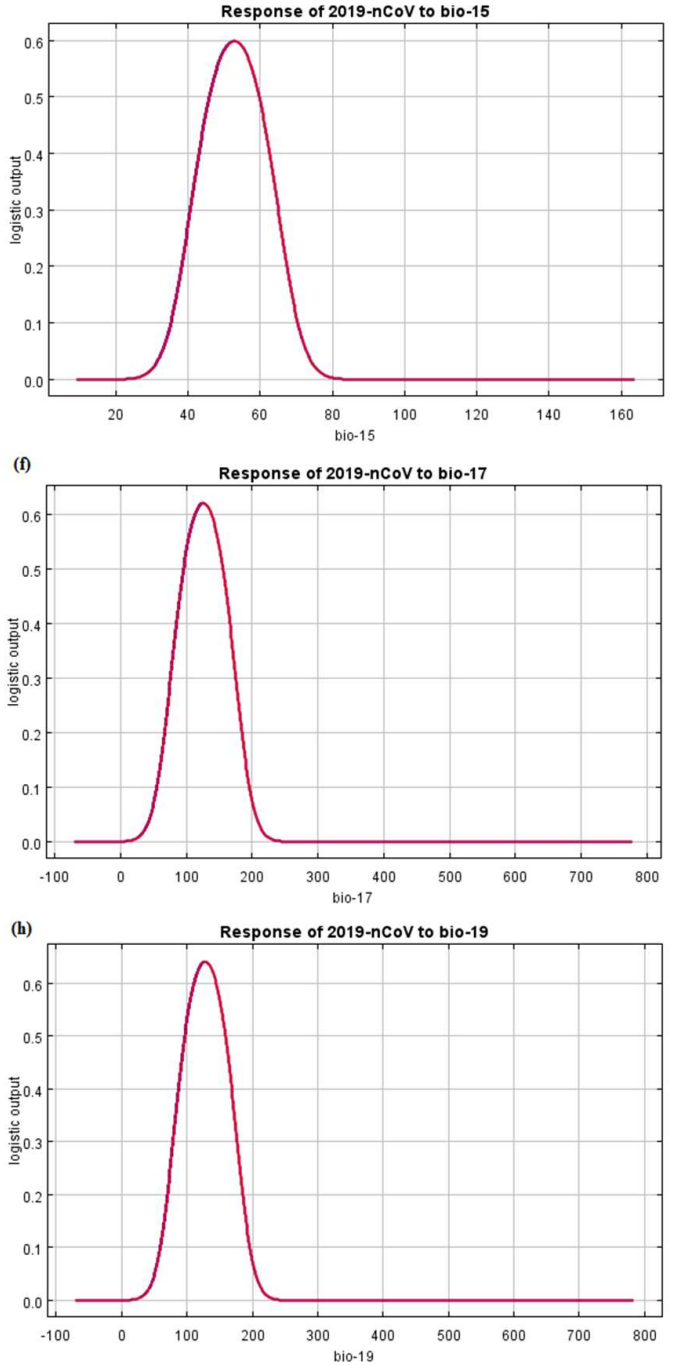

Figure 3. Response curve of biometeorological factors representing precipitation. 
In Figure. 3, peak response curves appear with annual precipitation (bio-12) approximately $1250 \mathrm{~mm}$, precipitation in the wettest month (bio-13) approximately $210 \mathrm{~mm}$, precipitation in the driest month (bio-14) approximately $30 \mathrm{~mm}$, precipitation in the wettest quarter (bio-16) approximately $600 \mathrm{~mm}$, precipitation in the driest quarter (bio-17) approximately $120 \mathrm{~mm}$, precipitation in the warmest quarter (bio-18) approximately 600 $\mathrm{mm}$, and precipitation in the coldest quarter (bio-19) approximately $120 \mathrm{~mm}$. The risk of a SARS-CoV-2 outbreak is highest under these precipitation conditions.

\subsection{Jackknife test of variable importance}

Figure 4 shows that the environmental variable with the highest gain when used in isolation was bio-19, which appears to have the most useful information by itself. The environmental variable with the largest decrease in gain when omitted is bio-06, which appears to have the most information that is not present in the other variables.

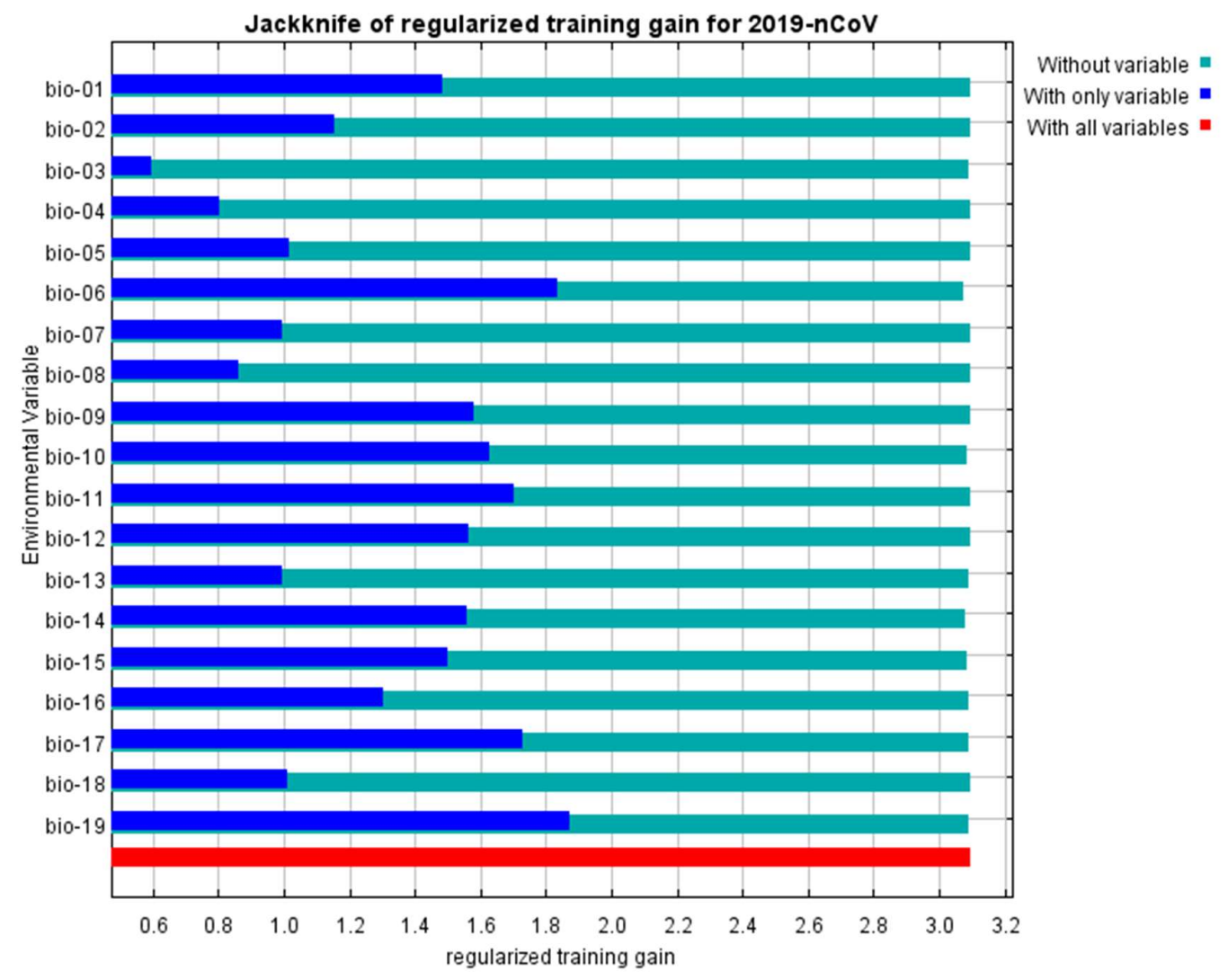

Figure 4. Jackknife test of variable importance.

\subsection{Model validation}



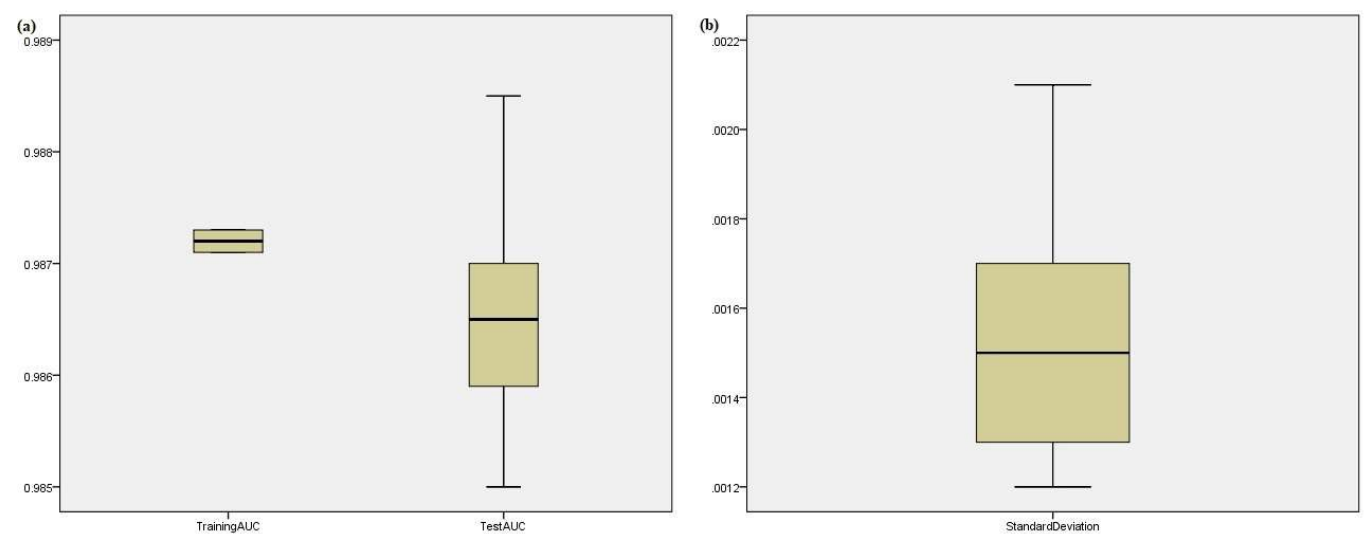

Figure 5. (a) Variations in the area under the receiver operating characteristic curve (AUC) for training localities (AUC training) and AUC for test localities (AUC test); (b) Standard deviation with 95\% confidence intervals.

In Figure. 5, all AUC values were greater than 0.9; the mean AUCTest was 0.9866, and the mean AUCTrain was 0.9872. With 95\% confidence intervals, the average standard deviation was 0.0015 . In addition, the logistic output results of background data of the MaxEnt model were calculated using the PresenceAbsence package. We subsequently obtained a maximum sensitivity (Max-Sensitivity) of 0.989619, maximum specificity (Max-Specificity) 0.9719, TSS value 0.961519, and AUC value 0.99758; the AUC standard deviation (AUC.sd) was 0.000455 . This prediction model shows very high stability, and the results are scientific and credible.

\section{Discussion}

SARS-CoV-2 is a novel coronavirus strain that has never been found in humans until now. Individuals with SARS-CoV-2 infection have symptoms such as fever as well as respiratory symptoms including cough, shortness of breath, and difficulty breathing. In more severe cases, patients can develop pneumonia, SARS, kidney failure, and the infection can even lead to death. At present, there is no specific treatment for COVID-19, which has become the most challenging infectious disease worldwide because of its rapid spread and high variability. Temperature and precipitation are two important environmental factors affecting epidemics [24]. SARS-CoV-2 emerged during the winter, so it has been unclear how seasonal changes in temperature and precipitation would affect spread of the virus.

In this study, we explored this problem using a MaxEnt model based on the niche theory. We considered the effect of model complexity in the calculation results. The $\triangle \mathrm{AIC}$ value under different combination models was calculated with the ENMeval software package to select the most suitable MaxEnt model for SARS-CoV-2 research $[38,39$. The mean AUC obtained after calculating the selected model was higher than 0.95 (Fig. 5), and the Max-sensitivity, Max-specificity, and TSS value of the model obtained using "PresenceAbsence" were close to 1 . Previous researchers have mainly used the missing rate curve to compare and evaluate the MaxEnt model X, or a partial ROC scheme to test the local prediction ability and transfer ability of the model [40]. We used the R package "PresenceAbsence" to calculate model sensitivity and specificity. The range is -1 to 1 , with 1 indicating that the experimental result is the best and 0 or less that the performance of the model is very poor $[41,42,43]$.

From the previous relevant literature, the TSS value can be used to avoid evaluation bias caused by the positive rate of the sample, and it is a good value for measuring the accuracy of the model $[41,42,43]$. Therefore, the results of this experiment have a high degree of reliability.

The jackknife result graph is mainly used to measure the effect of variable factors on the fitness of the target species. The longer the blue band, the greater the impact on the 
fitness of the target species. When the green band is shorter than the red band, the variable contains more biological information than other variables [44]. In Fig. 4, the lowest temperature in the coldest month (bio-06) showed significant importance. The significant reduction in the gain value of bio-06 shows that the factor has special biological information that other variables do not. In addition, bio-06 also showed a very high contribution rate from the perspective of the contribution of each factor to the model (Table S3). Figure 4 shows that precipitation had a stronger influence than temperature, from the length of the blue band for SARS-CoV-2. The coldest season precipitation (bio-19) is particularly prominent. Several other variable factors (bio-14, bio-17) representing low precipitation showed much greater importance than high precipitation factors (bio-13, bio-16). Therefore, combining these points, we speculate that the virus is more suited to conditions of low temperature (approximately $0-17.5^{\circ} \mathrm{C}$, bio-01, bio-06) and low precipitation.

From the experimental results, we postulate that SARS-CoV-2 outbreaks are more likely under conditions of low temperature and low precipitation. Wang et al. proposed that high temperatures and high precipitation can reduce the spread of SARS-CoV-2, so our research results are basically consistent with that study. However, from the response curve results of the investigated factors (Fig. $2 b, 2 \mathrm{~g}$ ), the output value is higher than that of other variables when the temperature is $37^{\circ} \mathrm{C}$ (bio-05) and $31.5^{\circ} \mathrm{C}$ (bio-10) (logistic output $>0.65$ ). The logistic output is close to 1 , especially when the temperature is $31.5^{\circ} \mathrm{C}$ (bio$10)$, so we think that the risk of infection is very high under this temperature condition. At the same time, from results of the response curves (Fig. 3b, 3e, 3g), the output values of the bio-13, bio-16, and bio-18 peaks occurred when the average monthly precipitation was approximately $200 \mathrm{~mm}$. Therefore, even if the virus is more suited to survive under low temperatures and sparse precipitation, special vigilance is needed to detect the peak period of disease during the summer and autumn, especially around $31-37^{\circ} \mathrm{C}$ and when the average monthly precipitation is approximately $200 \mathrm{~mm}$. This is consistent with previous research results [26].

\section{Conclusions}

In this experiment, we sought to identify an optimal model to predict SARS-CoV-2 survival under varying climate conditions, and we evaluated the sensitivity and specificity of the selected model; our results showed extremely high reliability. From the experimental results, SARS-CoV-2 is most likely to survive under environmental conditions of low temperature and low precipitation. At the same time, the possibility of increased virus survival risk with high temperatures (above $30^{\circ} \mathrm{C}$ ) and high precipitation (approximately $200 \mathrm{~mm}$ ) should not be underestimated. In general, this study provides a basis for ongoing research into suitable climate conditions for the spread of SARS-CoV-2.

This section is not mandatory, but may be added if there are patents resulting from the work reported in this manuscript.

Author Contributions: “Conceptualization, B.W. and Z.X.; methodology, B.W.; software, B.W.; validation, R.H.K.., B.W. and Z.X.; formal analysis, B.W.; investigation, B.W.; resources, Z.X.; data curation, R.H.K; writing - original draft preparation, B.W.; writing - review and editing, R.H.K; visualization, R.H.K; supervision, Z.X.; project administration, Z.X.; funding acquisition, Z.X. All authors have read and agreed to the published version of the manuscript

Acknowledgments: Not applicable.

Conflicts of Interest: Authors declares no conflict of interest

\section{References}

1. Lu, H. (2020). Drug treatment options for the 2019-new coronavirus (2019-nCoV). Bioscience trends, 14, 69-71. http:// doi.org/10.5582/bst.2020.01020.

2. Wrapp, D., Wang, N., Corbett, K. S., Goldsmith, J. A., Hsieh, C. L., Abiona, O., Graham, B. S. \& McLellan, J. S. (2020). Cryo-EM structure of the 2019-nCoV spike in the prefusion conformation. Science, 367, 1260-1263. http:// doi.org/ 10.1126/science.abb2507.

3. Zhou, P., Yang, X. L., Wang, X. G., Hu, B., Zhang, L., Zhang, W., ... Shi, Z. L. (2020). A pneumonia outbreak associated with a 
new coronavirus of probable bat origin. Nature, 579, 270-273. http://doi.org/10.1038/s41586-020-2012-7.

4. Lam, T. T.-Y., Shum, M. H.-H., Zhu, H.-C., Tong Y.-G., Ni, X.-B., Liao Y.-S., ... Guan, Y. (2020). Identification of 2019-nCoV related coronaviruses in Malayan pangolins in southern China bioRxiv. https://doi.org/10.1101/2020.02.13.945485 .

5. Ruiz-Arrondo, I., Portillo, A., Palomar, A. M., Santibanez, S., Santibanez, P., Cervera, C. \& Oteo, J. A. (2020). Detection of SARSCoV-2 in pets living with COVID-19 owners diagnosed during the COVID-19 lockdown in Spain: A case of an asymptomatic cat with SARS-CoV-2 in Europe medRxiv. https://doi.org/ 10.1101/2020.05.14.20101444.

6. Wong, G., Bi, Y. H., Wang, Q. H., Chen, X. W., Zhang, Z. G. \& Yao, Y. G. (2020). Zoonotic origins of human coronavirus 2019 (HCoV-19 / SARS-CoV-2): why is this work important? Zoological research, 41, 213-219. https://doi.org/10.24272/j.issn.20958137.2020.031.

7. Leroy, E. M., Ar Gouilh, M., \& Brugere-Picoux, J. (2020). The risk of SARS-CoV-2 transmission to pets and other wild and domestic animals strongly mandates a one-health strategy to control the COVID-19 pandemic. One Health-Amsterdam, 100133. https://doi.org/ 10.1016/j.onehlt.2020.100133.

8. Peng, X., Xu, X., Li, Y., Cheng, L., Zhou, X. \& Ren, B. (2020). Transmission routes of 2019-nCoV and controls in dental practice. International journal of oral science, 12, 9. https://doi.org/10.1038/s41368-020-0075-9.

9. Hui, D. S., I. A. E, Madani, T. A., Ntoumi, F., Kock, R., Dar, O., ... Petersen, E. (2020). The continuing 2019-nCoV epidemic threat of novel coronaviruses to global health - The latest 2019 novel coronavirus outbreak in Wuhan, China. International journal of infectious diseases : IJID : official publication of the International Society for Infectious Diseases, 91, 264-266. https://doi.org/ 10.1016/j.ijid.2020.01.009.

10. Wrapp, D., Wang, N., Corbett, K. S., Goldsmith, J. A., Hsieh, C. L., Abiona, O., Graham, B. S. \& McLellan, J. S. (2020). Cryo-EM structure of the 2019-nCoV spike in the prefusion conformation. Science, 367, 1260-1263. http:// doi.org/ 10.1126/science.abb2507.

11. Rodo, X., Pascual, M., Fuchs G. \& Faruque, A. S. (2002). ENSO and cholera: a nonstationary link related to climate change? Proceedings of the National Academy of Sciences of the United States of America, 99, 12901-12906. https://doi.org/10.1073/pnas.182203999.

12. Anyamba, A., Chretien, J. P., Small, J., Tucker, C. J. \& Linthicum, K. J. (2006). Developing global climate anomalies suggest potential disease risks for 2006-2007. International journal of health geographics, 5, 60. https://doi.org/10.1186/1476-072X-5-60.

13. Gutierrez-Fonseca, P. E., Ramirez, A. \& Pringle, C. M. (2018). Large-scale climatic phenomena drive fluctuations in macroinvertebrate assemblages in lowland tropical streams, Costa Rica: The importance of ENSO events in determining long-term (15y) patterns. PloS one, 13, e0191781. https://doi.org/10.1371/journal.pone.0191781.

14. Tabachnick, W. J., 2016: Research Contributing to Improvements in Controlling Florida's Mosquitoes and Mosquito-borne Diseases. Insects, 7. https://doi.org/10.3390/insects7040050.

15. Bett, B., Kiunga, P., Gachohi, J., Sindato, C., Mbotha, D., Robinson, T., Lindahl, J. \& Grace, D. (2017). Effects of climate change on the occurrence and distribution of livestock diseases. Preventive veterinary medicine, 137, 119-129. https://doi.org/10.1016/j.prevetmed.2016.11.019.

16. Kakarla, S. G., Caminade, C., Mutheneni, S. R., Morse, A. P., Upadhyayula, S. M., Kadiri, M. R.\& Kumaraswamy, S. (2019). Lag effect of climatic variables on dengue burden in India. Epidemiology and infection, 147, e170. https://doi.org/10.1017/S0950268819000608.

17. Silva-Caso, W., Espinoza-Espiritu, W., Espejo-Evaristo, J., Carrillo-Ng, H., Aguilar-Luis, M. A., Stimmler, L. \& Valle-Mendoza, J. Del. (2019). Geographical distribution, evaluation of risk of dengue and its relationship with the El Nino Southern Oscillation in an endemic region of Peru between 2004 and 2015. BMC research notes, 12, 498. https://doi.org/10.1186/s13104-019-4537-0.

18. Hjelle, B. \& Glass, G. E. (2000). Outbreak of hantavirus infection in the Four Corners region of the United States in the wake of the 1997-1998 El Nino-southern oscillation. The Journal of infectious diseases, 181, 1569-1573. https://doi.org/10.1086/315467.

19. Viboud, C., Pakdaman, K., Boelle, P. Y., Wilson, M. L., Myers, M. F., Valleron, A. J. \& Flahault, A. (2004). Association of influenza epidemics with global climate variability. European journal of epidemiology, 19, 1055-1059. https://doi.org/10.1007/s10654-0042450-9.

20. Lin, H., Zou, H., Wang, Q., Liu, C., Lang, L., Hou X. \& Li, Z. (2013). Short-term effect of El Nino-Southern Oscillation on pediatric hand, foot and mouth disease in Shenzhen, China. PloS one, 8, e65585. https://doi.org/10.1371/journal.pone.0065585.

21. Chan, J. Y., Lin, H. L. \& Tian, L. W. (2014). Meteorological factors and El Nino Southern Oscillation are associated with paediatric varicella infections in Hong Kong, 2004-2010. Epidemiology and infection, 142, $1384-1392$. https://doi.org/10.1017/S0950268813002306.

22. Oluwole, O. S. (2015). Seasonal Influenza Epidemics and El Ninos. Frontiers in public health, 3 , 250. https://doi.org/10.3389/fpubh.2015.00250.

23. Peci, A., Winter, A. L., Li, Y., Gnaneshan, S., Liu J., Mubareka, S. \& Gubbay, J. B. (2019). Effects of Absolute Humidity, Relative Humidity, Temperature, and Wind Speed on Influenza Activity in Toronto, Ontario, Canada. Applied and environmental microbiology, 85. https://doi.org/10.1128/AEM.02426-18.

24. Qasim Bukhari, Y. J. (2020). Will coronavirus pandemic diminish by summer? Available SSRN. https://ssrn.com/abstract=3558757.

25. Wang,J., K. T., Feng, K. Lin, X., Lv W., Chen K. \& Wang, F. (2020). High Temperature and High Humidity Reduce the Transmission of COVID-19 Available at SSRN 3551767. http://dx.doi.org/10.2139/ssrn.3551767.

26. Menebo, M. M. (2020). Temperature and precipitation associate with Covid-19 new daily cases: A correlation study between weather and Covid-19 pandemic in Oslo, Norway. Science of the total environment, 737, 139659. http://dx.doi.org/10.1016/j.scitotenv.2020.139659. 
27. Phillips, S. J. (2004). A maximum entropy approach to species distribution modeling. Proceedings of the twenty-first international conference on Machine learning. Proceedings of the Twenty-First International Conference on Machine Learning, 655-662. https://doi.org/10.1145/1015330.1015412.

28. Fekede, R. J., van Gils, H., Huang, L. \& Wang, X. (2019). High probability areas for ASF infection in China along the Russian and Korean borders. Transboundary and emerging diseases, 66, 852-864. https://doi.org/10.1111/tbed.13094.

29. Tarrant, J., Cilliers, D., du Preez, L. H. \& Weldon, C. (2013). Spatial assessment of amphibian chytrid fungus (Batrachochytrium dendrobatidis) in South Africa confirms endemic and widespread infection. PloS one, 8, e69591. https://doi.org/10.1371/journal.pone.0069591.

30. Sehgal, R. N., Buermann, W., Harrigan, R. J., Bonneaud, C., Loiseau, C., Chasar, A., ... Smith, T. B. (2011). Spatially explicit predictions of blood parasites in a widely distributed African rainforest bird. Proceedings. Biological sciences, 278, 1025-1033. https://doi.org/10.1098/rspb.2010.1720.

31. Bui, C. M., Gardner, L., MacIntyre, C. R. \& Sarkar, S. (2017). Correction: Influenza A H5N1 and H7N9 in China: A spatial risk analysis. PloS one, 12, e0176903. https://doi.org/10.1371/journal.pone.0176903.

32. Li, X. H., Tian, H. D., Heiner M. \& Li, D. M. (2011). Global occurrence and spread of highly pathogenic avian influenza virus of the subtype H5N1. Avian diseases, 55, 21-28. https://doi.org/10.1637/9306-031710-Reg.1.

33. Arabi, Y. M., Alothman, A., Balkhy, H. H., Al-Dawood, A., AlJohani, S., Al Harbi, S., ... And the, M. t. g. (2018). Treatment of Middle East Respiratory Syndrome with a combination of lopinavir-ritonavir and interferon-beta1b (MIRACLE trial): study protocol for a randomized controlled trial. Trials, 19, 81. https://doi.org/10.1186/s13063-017-2427-0.

34. Lu, H., Stratton, C. W. \& Tang, Y. W. (2020). Outbreak of pneumonia of unknown etiology in Wuhan, China: The mystery and the miracle. Journal of medical virology, 92, 401-402. https://doi.org/10.1002/jmv.25678.

35. Zhou, P., Yang, X. L., Wang, X. G., Hu, B., Zhang, L., Zhang, W., ... Shi, Z. L. (2020). A pneumonia outbreak associated with a new coronavirus of probable bat origin. Nature, 579, 270-273. http://doi.org/10.1038/s41586-020-2012-7.

36. Wang, Y., Fan, G., Salam, A., Horby, P., Hayden, F. G., Chen, C., Pan, J., Zheng, J., Lu, B., Guo, L., Wang, C. \& Cao, B. (2020). Comparative Effectiveness of Combined Favipiravir and Oseltamivir Therapy Versus Oseltamivir Monotherapy in Critically Ill Patients With Influenza Virus Infection. The Journal of infectious diseases, 221, 1688-1698. https://doi.org/10.1093/infdis/jiz656.

37. Hijmans, R. J., Cameron, S. E., Parra, J. L. Jones P. G. \& Jarvis, A. (2005). Very high resolution interpolated climate surfaces for global land areas. International Journal of clmatology, 25, 1965-1978. https://doi.org/10.1002/joc.1276.

38. Cobos, M. E., Peterson, A. T., Barve, N. \& Osorio-Olvera, L. (2019). kuenm: an R package for detailed development of ecological niche models using Maxent. PeerJ, 7. https://doi.org/10.7717/peerj.6281

39. Muscarella, R., Galante, P. J., Soley-Guardia, M., Boria, R. A., Kass, J. M., Uriarte, M. \& Anderson, R. P. (2014). ENMeval: An R package for conducting spatially independent evaluations and estimating optimal model complexity for MAXENT ecological niche models. Methods in Ecology and Evolution, 5, 1198-1205. https://doi.org/10.1111/2041-210X.12261.

40. Peterson, A. T., Papeş, M. \& Soberón, J. (2008). Rethinking receiver operating characteristic analysis applications in ecological niche modeling. Ecological Modelling, 213, 63-72. https://doi.org/10.1016/j.ecolmodel.2007.11.008.

41. Allouche, O., Tsoar, A. \& Kadmon, R. (2006). Assessing the accuracy of species distribution models: prevalence, kappa and the true skill statistic (TSS). Journal of Applied Ecology, 43, 1223-1232. https://doi.org/10.1111/j.1365-2664.2006.01214.x.

42. Liu, C. R., Berry, P. M., Dawson, T. P. \& Pearson, R. G. (2005). Selecting thresholds of occurrence in the prediction of species distributions. Ecography, 28, 385-393. https://doi.org/10.1111/j.0906-7590.2005.03957.x.

43. Mothes, C. C., Stroud, J. T., Clements, S. L. \& Searcy, C. A. (2019). Evaluating ecological niche model accuracy in predicting biotic invasions using South Florida's exotic lizard community. Journal of Biogeography, 46, 432-441. https://doi.org/10.1111/jbi.13511.

44. Bai, D. F., Chen, P. J., Atzeni, L., Cering, L., Li, Q. \& Shi, K. (2018). Assessment of habitat suitability of the snow leopard (Panthera uncia) in Qomolangma National Nature Reserve based on MaxEnt modeling. Zoological research, 39, $373-386$. https://doi.org/10.24272/j.issn.2095-8137.2018.057. 